\title{
REDUÇÃO ENZIMÁTICA DO 4-(DIMETILAMINO)BENZALDEÍDO COM PEDAÇOS DE CENOURA (Daucus carota): UM EXPERIMENTO SIMPLES NA COMPREENSÃO DA BIOCATÁLISE
}

\author{
Álvaro Takeo Omori*, Viviane Barbosa Portas e Camila de Souza de Oliveira \\ Centro de Ciências Naturais e Humanas, Universidade Federal do ABC, R. Santa Adélia, 166, 09210-170 Santo André - SP, \\ Brasil
}

Recebido em 19/5/11; aceito em 8/8/11; publicado na web em 26/9/11

\begin{abstract}
ENZYMATIC REDUCTION OF 4-(DIMETHYLAMINO)BENZALDEHYDE WITH CARROT BITS (Daucus carota): A SIMPLE EXPERIMENT FOR UNDERSTADING BIOCATALYSIS. The present paper describes a simple, low-costly and environmentally friendly procedure for reduction of 4-(dimethylamino)benzaldehyde using carrot bits in water. This interdisciplinary experiment can be used to introduce the concepts of biocatalysis and green chemistry to undergraduate students.
\end{abstract}

Keywords: biocatalysis; reduction of carbonyl compounds; green chemistry.

\section{INTRODUÇÃO}

A abordagem interdisciplinar na geração do conhecimento é um dos grandes desafios na educação em todas as áreas das Ciências Naturais. Porém, na química orgânica, por exemplo, grande parte dos experimentos aplicados em laboratórios didáticos para alunos de graduação não consegue integrar conhecimentos de outras disciplinas.

Além disso, existe também a dificuldade de aquisição de reagentes químicos específicos em um laboratório didático de química orgânica. $\mathrm{O}$ alto custo, as taxas de importação e a possibilidade de atrasos são alguns entraves que podem prejudicar o sucesso da disciplina experimental. Desta maneira, torna-se bastante atrativa a aplicação de experimentos com materiais de baixo custo e de alta disponibilidade. ${ }^{1}$

De forma simplificada, é apresentado um experimento de baixo custo, facilmente executável e contextualizado em diversas áreas, como Bioquímica, Química Orgânica e Química Verde. Consiste basicamente em uma reação de redução de um aldeído a um álcool utilizando enzimas provenientes de uma leguminosa altamente disponível (Daucus carota), cenoura. Esta prática visa à familiarização dos alunos com os conceitos da biocatálise. ${ }^{2}$

A biocatálise consiste no uso de catalisadores naturais - as enzimas - para realizar transformações químicas em compostos orgânicos. É uma ferramenta bastante versátil e está cada vez mais presente na indústria química. ${ }^{3}$ A princípio, todos os seres vivos são fontes de biocatalisadores e as enzimas presentes podem ser utilizadas nos mais diversos tipos de reações orgânicas. ${ }^{4}$

Os biocatalisadores apresentam características que os diferenciam dos catalisadores químicos, e estão intrinsecamente ligados aos princípios da Química Verde. ${ }^{5}$ Dentre estas características podem-se citar como exemplos: condições brandas de reação, pois o solvente utilizado geralmente é a água; o uso de reagentes degradáveis, uma vez que os catalisadores são enzimas de plantas, animais, ou são micro-organismos e podem ser decompostos no ambiente após o uso.

Além disso, a biocatálise oferece uma grande seletividade do ponto de vista estereoquímico. ${ }^{6}$ Por exemplo, analisando a reação de redução de cetonas pró-quirais (que levam a produtos contendo centros quirais). Um dos agentes redutores mais utilizados na redução de cetonas é o boro-hidreto de sódio $\left(\mathrm{NaBH}_{4}\right)$. A Figura 1 ilustra a redução da acetofenona ao 1-feniletanol por dois métodos.

*e-mail: alvaro.omori@ufabc.edu.br

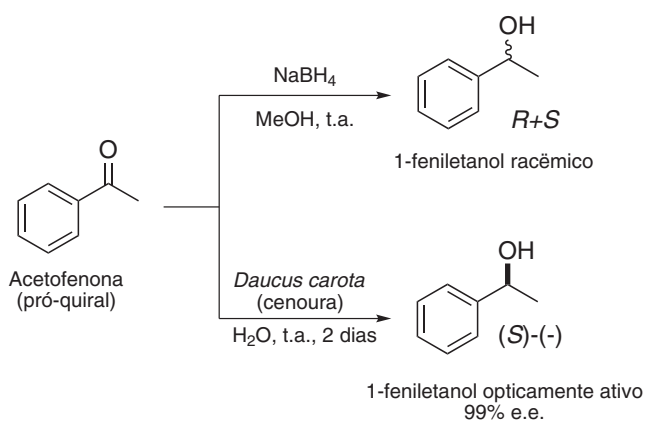

Figura 1. Redução da acetofenona utilizando boro-hidreto de sódio e com cenoura

$\mathrm{O} \mathrm{NaBH}_{4}$ é um agente redutor aquiral e, quando reage com cetonas pró-quirais, leva à formação de um álcool racêmico (dois isômeros com $50 \%$ cada). No entanto, a mesma transformação química, utilizando pedaços de cenoura (Daucus carota) leva à formação majoritária de um dos produtos. ${ }^{6}$

A cenoura tem sido usada com sucesso nas reduções de cetonas pró-quirais, apresentando como resultados, em alguns casos, uma conversão de $97 \%$ e um excesso enantiomérico (e.e.) acima de $99 \%$, sendo um dos biocatalisadores conhecidos mais eficientes. ${ }^{7}$ (Nota: as enzimas que catalisam estas reações são chamadas de desidrogenases, pertencentes a uma subclasse das oxidorredutases, enzimas responsáveis pelas reações de oxidação-redução). ${ }^{8}$

$\mathrm{O}$ crescente interesse no uso das plantas em biocatálise pode ser demonstrado no recente artigo de revisão de Cordell e colaboradores. ${ }^{1}$

Em resumo, é proposta uma prática que visa avaliar qualitativamente a atividade catalítica da cenoura na redução do reagente de Ehrlich (CAS [100-10-7]). Esta detecção pode ser feita através de uma análise de CCD (cromatografia em camada delgada) ou até mesmo através de técnicas espectroscópicas (RMN). No fim da reação o produto pode ser isolado através de uma extração líquido-líquido, seguida de uma purificação por cromatografia em coluna.

\section{PARTE EXPERIMENTAL}

O 4-(dimetilamino)benzaldeído (ACS 99\%, Sigma-Aldrich) e os solventes empregados (hexano, acetato de etila e metanol padrão P.A.- Vetec) foram utilizados sem prévia purificação. As análises de 
CCD foram efetuadas em cromatofolhas de alumínio (gel de sílica 60 ), com espessura de 0,2 mm, contendo indicador para $254 \mathrm{~nm}$.

\section{Redução do 4-(dimetilamino)benzaldeído}

O reagente 4-(dimetilamino)benzaldeído é comumente utilizado na determinação espectrofotométrica de hidrazinas ${ }^{9} \mathrm{e}$, também, na detecção de urobilinogênio na urina. ${ }^{10}$ Outras aplicações incluem seu uso como bloco de construção de moléculas mais complexas, por exemplo, na síntese da tricostatina A feita por Fleming e colaboradores. ${ }^{11}$

Já o produto obtido da redução, o álcool 4-(dimetilamino)benzílico, é também bastante utilizado como bloco de construção de moléculas mais complexas. ${ }^{12}$

\section{Procedimento para a reação biocatalítica}

Este procedimento está ilustrado na Figura 2.
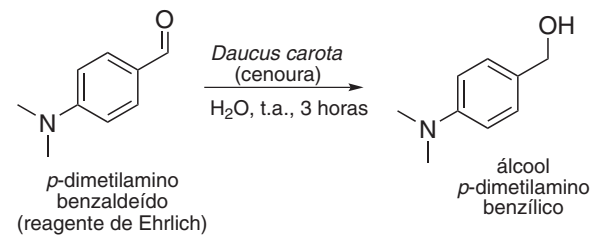

Figura 2. Redução do reagente de Ehrlich utilizando pedaços de cenoura

Uma cenoura fresca foi adquirida em um mercado local, lavada com água corrente e, em seguida, cortada em fatias de aproximadamente $0.5 \mathrm{~cm}$ (não é necessário descascar). Os pedaços foram pesados em um Erlenmeyer de $125 \mathrm{~mL}$ com uma balança semianalítica até obter-se aproximadamente $10 \mathrm{~g}$ de catalisador. Em seguida, foram adicionados $40 \mathrm{~mL}$ de água destilada e $50 \mathrm{mg}$ do para-(dimetilamino) benzaldeído (Figura 3).

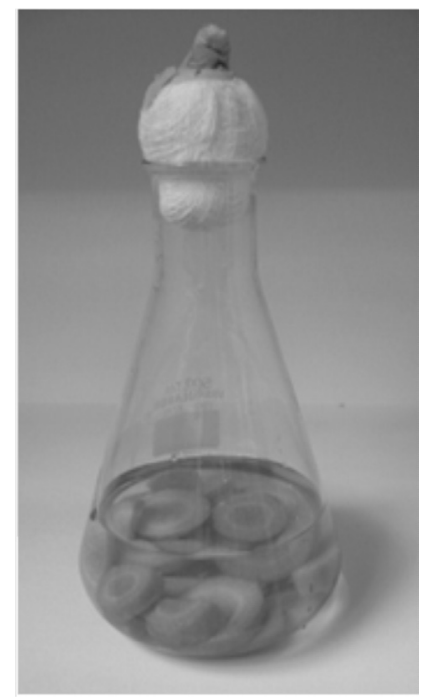

Figura 3. Sistema reacional usando pedaços de cenoura

O Erlenmeyer foi levado ao agitador rotativo (temperatura ambiente, $200 \mathrm{rpm}$ ), onde permaneceu pelo tempo disponível de aula (no nosso caso, $3 \mathrm{~h}$ ). Decorrido este tempo, uma alíquota de $2 \mathrm{~mL}$ foi retirada da reação e transferida para um tubo tipo Falcon de 15 $\mathrm{mL}$. A este tubo foi adicionado $1 \mathrm{~mL}$ de acetato de etila (AcOEt).

O tubo foi agitado em um vortex e levado para centrífuga por $5 \mathrm{~min}$, a aproximadamente $2500 \mathrm{rpm}$. Esta extração também pode ser feita manualmente, sem necessidade de vortex e/ou centrífuga.

Uma alíquota também foi retirada e os componentes orgânicos extraídos após 24 h de reação. Estes tubos contendo as fases orgânicas foram diretamente utilizados para a análise de CCD junto com o produto padrão preparado durante o período de agitação.

\section{Procedimento para a síntese química do produto (padrão)}

Durante o intervalo de $3 \mathrm{~h}$ de agitação da reação com a cenoura, foi feita a síntese química do produto (padrão).

Aproximadamente $10 \mathrm{mg}$ do reagente de Ehrlich foram adicionados a um balão de $15 \mathrm{~mL}$ munido com barra magnética. Metanol foi adicionado $(5 \mathrm{~mL})$ ao balão e o sistema foi resfriado sob agitação a $0{ }^{\circ} \mathrm{C}$. Uma pequena quantidade de boro-hidreto de sódio (ponta de espátula) foi adicionada à reação e o sistema foi agitado por mais 15 min de $0{ }^{\circ} \mathrm{C}$ à temperatura ambiente. Após este tempo, já foi possível retirar uma alíquota para servir como padrão para análise de CCD.

\section{Análise de cromatografia em camada delgada (CCD)}

Para análise de CCD, foi utilizada uma solução de hexano e acetato de etila na proporção 1:4 como fase móvel. Foram aplicados quatro pontos (Reagente, produto da síntese química e as alíquotas de 3 e 24 h de reação). Após marcação da distância percorrida pelo eluente, foram marcadas sob luz UV as distâncias percorridas pelas amostras e, em seguida, foram calculados os $\mathrm{R}_{\mathrm{f}}$ do reagente e do produto.

\section{Isolamento do produto (opcional)}

Após o término da reação, a fase líquida foi transferida para dois tubos tipo Falcon de $50 \mathrm{~mL}$ e, em seguida, foram adicionados $15 \mathrm{~mL}$ de acetato de etila. Os tubos foram agitados em vortex por alguns minutos e, então, levados à centrífuga por $10 \mathrm{~min}$, a aproximadamente $2500 \mathrm{rpm}$.

A fase orgânica foi separada e transferida a um Erlenmeyer de 125 mL e, em seguida, foi adicionado sulfato de sódio $\left(\mathrm{Na}_{2} \mathrm{SO}_{4}\right)$ anidro. A fase foi filtrada em um balão de fundo redondo de $50 \mathrm{~mL}$ e levado para a destilação sob pressão reduzida. O resíduo foi purificado através de cromatografia em coluna em sílica, utilizando uma mistura gradiente de hexano:acetato de etila (2:1 a 1:4) como eluente.

\section{RESULTADOS E DISCUSSÃO}

A Figura 4 mostra a cromatografia de camada fina após contato com o eluente (hexano:acetato 1:4) com as amostras de reagente, produto da redução química, reação com cenoura após 3 e 24 h, nesta ordem. Pela figura, observa-se a formação de um produto da redução enzimática com o mesmo Rf do produto da redução química.

Observou-se uma baixa conversão em 3 h de reação apesar de que, neste tempo de reação, já foi possível visualizar a formação do produto por CCD. A alíquota de 24 h de reação já mostrou uma melhor conversão, apesar de ainda haver reagente. Esta observação corrobora com o trabalho de Yang e colaboradores em que, após o estudo mais aprofundado desta reação com acetofenona, foi observado que o tempo ideal para a reação de redução com pedaços de cenoura é de aproximadamente 48 h. ${ }^{13}$

A fim de avaliar a repetibilidade desta reação, aplicou-se este experimento em uma disciplina de Práticas de Química Verde e foi observado que, em 12 experimentos, apenas dois deles apontaram a não formação do produto, provavelmente devido à inatividade do catalisador empregado, no qual vários fatores como método de cultivo, espécie utilizada, procedência e validade da cenoura podem estar associados. 


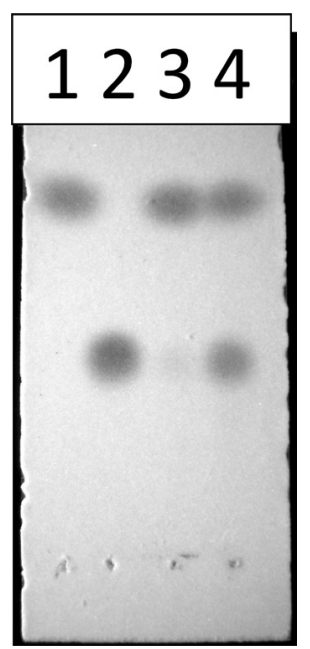

Figura 4. Placa de CCD contendo amostras sob luz $U V:$ 1. reagente $(R f=$ $0,7)$, 2. produto padrão $(R f=0,4), 3$. reação enzimática após $3 h$, 4. reação enzimática após $24 \mathrm{~h}$

Um dos grandes questionamentos sobre esta reação de redução de grupos carbonilícos mediada por cenoura se refere à fonte enzimática. Gonzalez e colaboradores levantaram a hipótese de que as enzimas contidas em micro-organismos endofíticos da cenoura seriam os principais responsáveis pela atividade biocatalítica. ${ }^{14}$ Esta hipótese foi investigada, isolando estes micro-organismos e submetendo-os às mesmas reações. No caso, foi observada a mesma reatividade da cenoura; além disso, o uso de fungicidas e bactericidas nos pedaços de cenoura praticamente inibiu a atividade catalítica.

A caracterização do produto foi feita através da análise de RMN de ${ }^{1} \mathrm{H}$ e está de acordo com o publicado na literatura. ${ }^{15}$ Curiosamente, a análise do produto por cromatografia gasosa acoplada ao espectrômetro de massas apresentou um único pico com íon molecular de $\mathrm{m} / z$ $=254$. Este valor difere do produto esperado $(\mathrm{m} / \mathrm{z}=151)$ provavelmente devido à dimerização do reagente no injetor do cromatógrafo através de um mecanismo de condensação do tipo Mannich, ${ }^{16}$ como mostra a Figura 5.

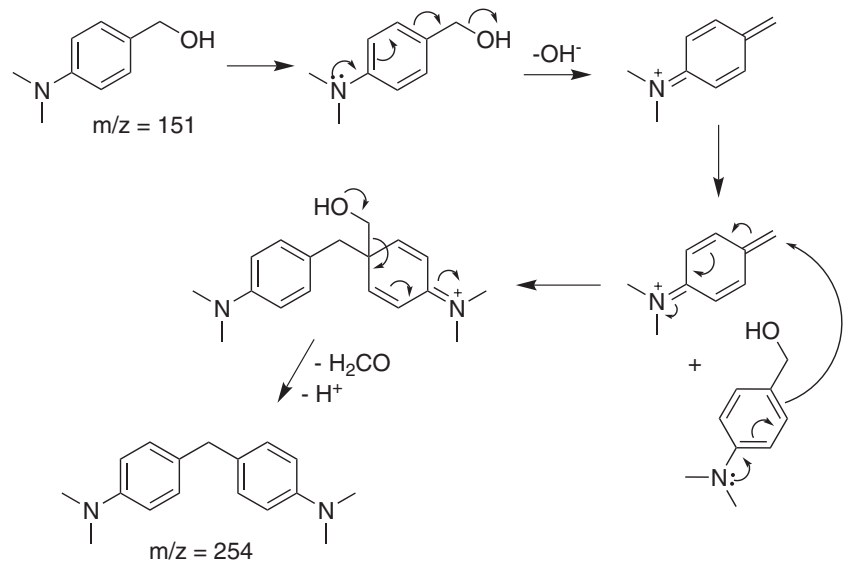

Figura 5. Mecanismo proposto para a formação do dímero de $\mathrm{m} / \mathrm{z}=254$ a partir do álcool 4-(dimetilamino)benzílico

\section{CONCLUSÃO}

A redução do 4-(dimetilamino)benzaldeído utilizando pedaços de cenoura levou ao álcool correspondente e o monitoramento desta reação pode ser feito utilizando cromatografia de camada delgada. Esta prática é de fácil execução, possui custo baixo e é interdisciplinar.
Como o tempo reacional é relativamente longo, este experimento pode ser feito em etapas sucessivas. É possível discutir durante o experimento vários aspectos da teoria de cromatografia. Por exemplo, diversos eluentes poderm ser empregados e ser abordada uma possível discussão sobre a influência da polaridade. Outros aspectos importantes incluem mecanismos de reação química e bioquímica, identificação de compostos por RMN, espectrometria de massas e estereoquímica. No final, os pontos positivos desta reação podem ser amplamente discutidos e correlacionados com os princípios da Química Verde e Biocatálise.

\section{MATERIAL SUPLEMENTAR}

No material suplementar, disponível gratuitamente em arquivo PDF em http://quimicanova.sbq.org.br, encontram-se os espectros de ressonância magnética nuclear dos produtos obtidos por via química e por via enzimática e os espectros de massas do reagente e do produto dimerizado.

\section{AGRADECIMENTOS}

À Central Analítica do Instituto de Química da USP pelas análises de RMN e CG-EM, à UFABC pela estrutura ao CNPq e à FAPESP pelo apoio financeiro.

\section{REFERÊNCIAS}

1. Cordell, G. A.; Lemos, T. L. G.; Monte, F. J. Q.; Mattos, M. C.; J. Nat. Prod. 2007, 70, 478. Este foi o $3^{\circ}$ artigo mais acessado deste periódico em 2007.

2. Marsaioli, A. J.; Porto, A. L. M.; Biocatálise e Biotransformação Fundamentos e Aplicações, Schoba: Salto, 2010, vol. 1.

3. Liese, A.; Seelbach, K.; Wandrey, C.; Industrial Biotransformations, $1^{\text {st }}$ ed., Wiley-VCH: Weinheim, 2000.

4. Faber, K.; Biotransformations in Organic chemistry, $4^{\text {th }}$ ed., SpringerVerlag: Berlin, 2000.

5. Lenardão, E. J.; Freitag, R. A.; Dabdoub, M. J.; Batista, A. C. F.; Silveira, C. C.; Quim. Nova 2003, 26, 123; Prado, A. G. S.; Quim. Nova 2003, 26, 738 .

6. Zuin, V. G.; Correa, A. G.; Química verde - Fundamentos e Aplicações, $1^{\text {a }}$ ed., Edufscar: São Carlos, 2009.

7. Yadav, J. S.; Nanda, S.; Reddy, P. T.; Rao, A. B.; J. Org. Chem. 2002, 67, 3900; Comasseto, J. V.; Omori, A. T.; Porto, A. L. M.; Andrade, L. H.; Tetrahedron Lett. 2004, 45, 473; Lacheretz, R.; Pardo, D. G.; Cossy, J.; Org. Lett. 2009, 11, 1245; Blanchard, N.; van de Weghe, P.; Org. Biomol. Chem. 2006, 4, 2348.

8. Voet, D.; Voet, J. G.; Biochemistry, $2^{\text {nd }}$ ed.; Wiley, 1995, cap. 12; Matsuda, T.; Yamanaka, R.; Nakamura, K.; Tetrahedron: Asymmetry 2009, 20,513 .

9. Watt, G. W.; Chrisp, J. D.; Anal. Chem.1952, 24, 2006.

10. Wilson, T. M.; Davidson, L. S. P.; Br. Med. J. 1949, 884.

11. Fleming, I.; Iqbal, J.; Krebs, E. P.; Tetrahedron 1983, 39, 841.

12. Enomoto, H.; Morikawa, Y.; Miyake, Y.; Tsuji, F.; Mizuchi, M.; Suhara, H.; Fujimura, K.; Horiuchi, M.; Ban, M.; Bioorg. Med. Chem. Lett. 2009, 19, 442; Chou, S. P.; Yeh, Y.; Tetrahedron Lett. 2001, 42, 1309.

13. Chang, X.; Yang, Z. H.; Zeng, R.; Yang, G.; Yan, J. B.; Chin. J. Chem. Eng. 2010, 18, 1029.

14. Rodríguez, P.; Barton, M.; Aldabalde, V.; Onetto, S.; Panizza, P.; Menéndez, P.; Gonzalez, D.; Rodríguez, S. J. Mol. Catal. B: Enzym. 2007, 49, 11.

15. Shaikh, N. S.; Junge, K.; Beller, M.; Org. Lett. 2007, 9, 5429.

16. Takahashi, H.; Kashiwa, N.; Kobayashi, H.; Hashimoto, Y.; Nagasawa, K.; Tetrahedron Lett. 2002, 43, 5751. 